https://helda.helsinki.fi

International fisheries agreements and non-consumptive values

Pintassilgo, Pedro

2018-07

Pintassilgo , P , Laukkanen , M , Gronbaek, L \& Lindroos , M 2018 , ' International fisheries

agreements and non-consumptive values ' , Fisheries Research , vol. 203 , pp. 46-54 . https://doi.org/10.1016/j.fishre

http://hdl.handle.net/10138/313340

https://doi.org/10.1016/j.fishres.2017.07.004

cc_by_nc_nd

acceptedVersion

Downloaded from Helda, University of Helsinki institutional repository.

This is an electronic reprint of the original article.

This reprint may differ from the original in pagination and typographic detail.

Please cite the original version. 
Research

Elsevier Editorial System(tm) for Fisheries

Manuscript Draft

Manuscript Number: FISH7382R1

Title: International Fisheries Agreements and Non-consumptive Values

Article Type: SI: Game Theory and Fisheries

Keywords: coalition games; international fisheries agreements; nonconsumptive values; non-use values; shared fish stocks.

Corresponding Author: Dr. Pedro Pintassilgo,

Corresponding Author's Institution: Universidade do Algarve

First Author: Pedro Pintassilgo

Order of Authors: Pedro Pintassilgo; Marita Laukkanen; Lone Grønbæk ; Marko Lindroos

Manuscript Region of Origin: FINLAND 


\section{Revision Notes}

Cover letter

Editor

Fisheries Research

Faro, Portugal, January 28, 2017

Issue: Revision of paper FISH7382 - submitted to Special Issue on "Game Theory and Fisheries".

Dear Editor,

We have revised our paper according to the suggestions made by the referees. Together with the revised version, in which all changes are marked in blue color, we also submit two files with detailed answers to the referees.

Yours Sincerely,

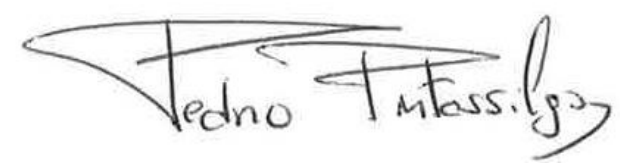

Pedro Pintassilgo (corresponding author)

University of Algarve, Faculty of Economics, E-mail: ppintas@ualg.pt 


\title{
International Fisheries Agreements and Non-consumptive Values
}

\begin{abstract}
The management of internationally shared fish stocks is a major economic, environmental and political issue. According to international law, these resources should be managed cooperatively under international fisheries agreements (IFAs). This paper studies the formation and stability of IFAs through a coalition game that accounts for both direct consumptive values (harvesting profits) and non-consumptive values of the fish stock per se. The results show that accounting for non-consumptive values helps conserve the fish stock in that equilibrium fishing efforts are smaller and fish stock larger than without non-consumptive values under all possible coalition scenarios (full, partial and no cooperation). However, considering non-consumptive values does not affect the outcome of the game in terms of the prospects for cooperation: even with substantial non-consumptive benefits, the outcome is full non-cooperation. Hence, the trap of non-cooperation in international fisheries management cannot be overcome simply by explicitly accounting for non-consumptive values within IFAs. It is suggested that strengthening the role of IFAs and limiting the ability of non-member countries to free-ride be further investigated as measures fostering cooperation.
\end{abstract}

Keywords: coalition games, international fisheries agreements, non-consumptive values, non-use values, shared fish stocks. 


\section{Introduction}

Disputes over the management of shared fish stocks seem everlasting. Conflicts are particularly persistent when a fish stock is harvested by several countries in the high seas. Countries and groups with a stake to such a shared stock may have markedly different views of the optimal management strategy. Despite the mutual advantages to be gained through cooperative harvesting, establishing and sustaining cooperation has proven difficult.

The strategic interactions pertaining to the harvesting of shared fish stocks have been studied extensively applying game theoretic modeling tools, starting with the seminal paper by Munro (1979). A survey on the developments made in the three decades following Munro's seminal work can be found in Bailey et al. (2010). Over the recent years applications of game theory to the management of shared fish stocks continued to emerge (e.g. Brandt and Kronbak, 2010; Breton and Keoula, 2014; Hannesson, 2013; Jensen et al. 2015; Kulmala et al., 2013; Punt et al., 2013). A topic that received particular attention is the formation of international fisheries agreements (IFAs), which involve several countries joining together to manage a fish stock. Coalition formation games have become the standard tool to address the formation of IFAs since the introduction of the partition function game approach by Pintassilgo (2003). The coalition formation literature on IFAs has been steadily growing (Pintassilgo et al., 2015).

The game theoretic literature on shared fishery resources has largely focused on the payoff derived from harvesting fish. Yet a significant part of the total economic value of marine resource stocks may be attributable to benefits aside from direct consumption of products from the stock (e.g., Ferrara and Missios, 1998; Loomis and White, 1996; Mazzanti, 2001; Turner et al., 2003). ${ }^{1}$ Non-consumptive value encompasses direct non-consumptive use value, such as watching fish, as well as non-use values ranging from existence values to option and bequest values (see e.g. Mazzanti, 2001). ${ }^{2}$ If resource managers are assumed to be maximizing overall net benefits, non-consumptive values cannot be ignored in deriving an optimal outcome (see e.g. Alexander, 2000; Ferrara and Missios, 1998; Yamazaki et al., 2010). However, despite the potentially significant role of non-consumptive values in determining optimal management strategies, the combination of game theory and non-consumptive values in the analysis of shared fishery resources is scarce - to our knowledge, only two previous papers, Missios and

\footnotetext{
${ }^{1}$ Measuring the non-consumptive values attributable to environmental resources has become an important research area within environmental economics (Smith, 2000). Such values cannot in general be measured based on market transactions. Non-market valuation methods have been developed to derive benefit estimates where market information is not available (see, e.g., Arrow et al., 1993). A common example of the application non-market valuation methods to fisheries includes the measurement of recreational values (e.g., Håkansson, 2008).

${ }^{2}$ Both direct and indirect non-consumptive values can be seen as part of ecosystem services, a concept popularized by the Millennium Ecosystem Assessment (2005).
} 
Plourde (1997) and Ferrara and Missios (1998), have addressed non-consumptive values and strategic considerations. These papers show in a two-country framework that non-consumptive values reduce the total harvest relative to the case of only consumptive values, and may have important implications for the strategic behavior of countries with an interest in the resource stock.

The contribution of the present paper is that it extends the analysis of coalition formation in fisheries management to the case where at least one country derives non-consumptive values from the resource stock. While many internationally shared fishery resources are harvested by several rather than by just two countries, the models developed in Ferrara and Missios (1998) and Missios and Plourde (1997) can only be applied to the case where a fish stock migrates across the boundaries between the waters of just two nations. Analyzing the potential for selfenforcing international agreements on fisheries management in this case calls for analyzing coalition formation rather than two-country bargaining solutions.

Ferrara and Missios (1998) considered a two-country, two period game where at least one of the countries receives benefits attributable to the size of the fish stock, and hence allow for nonconsumptive values. The model was used for studying the total harvest and catch shares between the two countries. ${ }^{3}$ The Nash bargaining approach was applied as a solution concept, whereby the product of the two countries objective functions was maximized over the two periods. The model was solved backwards by first computing the second period catch shares. In the first part of the paper only one country, labeled the home country, receives non-use benefits from the fish stock. The result is based on the equi-marginal principle where the marginal benefit from direct consumptive use is set equal to the marginal non-use value of the home country. This equality was used as a self-enforcement condition in the first period. The result from the first period is that accounting for non-use value increases the stock size and reduces harvest.

We show that considering non-consumptive values is not sufficient for avoiding the trap of noncooperation in a coalition formation framework: Although accounting for non-consumptive values decreases the aggregate fishing effort under all possible coalition structures (full, partial and no cooperation), the outcome of the game is full non-cooperation. This result persists regardless of the magnitude of the non-consumptive benefits. In their bargaining analysis Ferrara and Missios (1998) conclude that the equilibrium stock size increases with nonconsumptive values. We demonstrate that while cooperation and the inclusion of non-

\footnotetext{
${ }^{3}$ Missios and Plourde (1997) consider a similar model but a continuous time specification. Their analysis focuses on the total steady state stock and harvest; the sharing rule is not specified.
} 
consumptive values in the objective function work in the same direction in that both lead to the conservation of the shared fish stock, full non-cooperation remains the outcome of the game, even when all players assign non-consumptive value to the stock.

In our approach, as in Ferrara and Missios, players receive benefit from both harvest and the level of the fish stock. Similar approaches in a general resource extraction context include, among others, Alexander (2000), Conrad and Clark (1987), Harstad and Liski (2012) and Lasserre and Smulders (2013). Conrad and Clark (1987) is an early example of a social welfare function that attributes value to the stock itself, referred to as the preservation value of the stock by the authors. Alexander (2000) analyzed the implications of non-consumptive values for species' survival. He concluded that models and policies that fail to consider non-consumptive values are likely to result in inappropriately low optimal population levels. Harstad and Liski (2012) compared extraction levels by several non-cooperating resource users to socially optimal extraction levels in a model where each user values the stock as well as extraction from the stock. Their focus was on inefficiencies arising from strategic behavior, whereas solutions for overcoming such inefficiencies were left as a topic for future research. Furthermore, their stylized model setup assumed that the stock size is exogenously given, so conservation aspects were not addressed. Lasserre and Smulders (2013) modeled the interactions between renewable and non-renewable natural resources, allowing for the possibility that society derives direct utility from resource stocks. While Lasserre and Smulders did not carry out a full analysis of non-consumptive values and resource extraction, they concluded, based on surveys, that this link is of importance.

In a fisheries context, Yamazaki et al. (2010) showed that accounting for non-consumptive values is an important issue for optimal marine reserve design and substantially decreases the frequency of rotating of non-fishing areas. Finally, while non-consumptive values and strategic behavior among resource users has received relatively short shrift, game theory was incorporated as a tool for estimating non-use values already in the 1970's when Randall et al. (1974) suggested using bidding games to reveal respondents willingness to pay for environmental improvements in contingent valuation surveys.

The paper is organized as follows: Section 2 develops a bio-economic model and a coalition formation model that incorporate both harvesting and non-consumptive values of the fishery. The coalition formation game is solved backwards. Section 3 describes countries' optimal effort strategies in the second stage of the game and discusses the implications of non-consumptive values for equilibrium harvest levels under different coalition structures. Section 4 analyzes the countries' membership decision in the first stage of the game and discusses the effect of non- 
consumptive values on the size of the coalition. Section 5 extends the model to account for asymmetries in non-use values, before discussion and conclusion in Section 6.

\section{Bioeconomic model and coalition formation model with non-consumptive values}

Modelling the formation of an international fisheries agreement requires two main components: a bioeconomic model describing stock dynamics, harvest functions, revenues, fishing costs, and possible non-consumptive benefits; and a coalition formation model, that is, a game showing the strategic interactions between the different players, here countries. We next outline the bioeconomic model and the coalition formation game in Sections 2.1 and 2.2.

We consider three countries exploiting a transboundary fish stock. Each country receives consumptive benefits from harvest as well as non-consumptive benefits from the fish stock per se. The non-consumptive values considered here may entail both non-use values (option value, existence value, or bequest value) and non-consumptive use values (such as fish watching as recreational activity, or ecological functions). Initially we assume that the three countries are symmetric with regard to prices, costs, and non-consumptive values. The three-country setting is a modelling choice due to complexity arising from introducing a non-linear non-consumptive value component; a three-player game is analytically tractable yet maintains all the main components of a coalition formation game.

\subsection{The bioeconomic model}

By assumption, the growth of the fish stock follows a logistic growth function (2). Let $X$ denote the size of the fish stock, and $H_{i}$ and $E_{i}$ the harvest and fishing effort of an individual country $i$. The relation between the fish stock, the harvests, and the fishing efforts exerted by the three countries is given by the following three equations:

$$
\begin{aligned}
& \frac{d X}{d t}=G(X)-\sum_{i=1}^{3} H_{i} \\
& G(X)=r X\left(1-\frac{X}{k}\right) \\
& H_{i}=q E_{i} X
\end{aligned}
$$

where $r$ denotes the intrinsic growth rate of the fish stock, $k$ the carrying capacity of the ecosystem (and thus the equilibrium level of $X$ in the absence of harvesting), $q$ the catchability coefficient, and $t$ time. 
The variation of the stock level in time is given by the difference between stock growth $G(X)$ and total harvest (1). The inverted U-shaped logistic growth function (2) implies that stock growth increases up to a maximum value, often referred to as the maximum sustainable yield, and decreases thereafter. The harvest function of each country (3) is assumed to increase linearly with the catchability coefficient, its own the fishing effort, and the stock level.

The steady state relation between the stock level and the total fishing effort can be obtained by substituting (2) and (3) into (1) and setting $d X / d t=0$, which yields

$$
X^{*}=\frac{k}{r}\left(r-q \sum_{i=1}^{3} E_{i}\right) \text {. }
$$

As shown by equation (4), the equilibrium stock is decreasing in the total fishing effort of the three countries, $\sum_{i=1}^{3} E_{i}$.

We focus on the symmetric case where the countries face an identical price of fish and cost of fishing effort. The payoff of each country is given by the sum of the commercial profits from harvest (direct consumptive value) and non-consumptive value:

$$
\Pi_{i}=p H_{i}-c E_{i}+v_{i}(X)
$$

where $p$ is the price of fish, $c$ the cost per unit of effort, and $v_{i}(X)$ the non-consumptive value of the fish stock for country $i$.

Regarding the functional form specification for the non-consumptive value $v_{i}(X)$, we assume a strictly concave function implying that society attributes a decreasing marginal value to the stock for non-consumptive purposes. This is a standard assumption in natural resource valuation (Freeman III, 2003) and has also been adopted in previous work in the fisheries literature (e.g., Liu, 2013; Olaussen et al., 2015).

In our formulation, the non-consumptive value is zero when the stock is extinct: $v_{i}(0)=0$. Moreover, we assume that the non-consumptive value increases with the stock until the carrying capacity of the environment is reached and obtains its maximum at the carrying capacity $k$, which imply that $v_{i}^{\prime}(X)>0, \forall 0 \leq X<k$, and $v_{i}^{\prime}(k)=0$. That is, if the stock increases beyond the carrying capacity of the ecosystem, the marginal non-consumptive value from additional stock becomes negative. Finally, we also assume that the non-consumptive value increases at a 
decreasing rate with the stock level: $v_{i}^{\prime \prime}(X)<0$. We incorporate these properties by adopting the quadratic functional form specification:

$v_{i}(X)=A_{i} X-B_{i} X^{2}$

We initially assume that the non-consumptive values are symmetric: $A_{i}=A, B_{i}=B$ and $v_{i}(X)=v(X)$ for all $i$ (we will relax this assumption in section 5). The assumption that $v^{\prime}(k)=0$ yields the following parameter relation: $B=\frac{A}{2 k}$. Thus, the symmetric nonconsumptive value function can be rewritten as:

$v(X)=A X\left(1-\frac{X}{2 k}\right)$

The non-consumptive value function increases with the parameter $A$. Hence, this parameter can be interpreted as a direct measure of the magnitude of the non-consumptive benefits.

Inserting (3), (4) and (7) into (5), each country's payoff can be written as:

$$
\Pi_{i}=p q E_{i} \frac{k}{r}\left(r-q\left(\sum_{\ell=1}^{3} E_{\ell}\right)\right)-c E_{i}+A \frac{k}{r}\left(r-q\left(\sum_{\ell=1}^{3} E_{\ell}\right)\right)\left(1-\frac{1}{2 r}\left(r-q\left(\sum_{\ell=1}^{3} E_{\ell}\right)\right)\right) .
$$

Equation (8) indicates that an increase in the fishing effort by one country creates a negative externality to the other countries, through a decrease in the equilibrium stock level that reduces the other countries' revenue and non-consumptive value.

\subsection{Coalition formation model}

We model the formation of an international fishery agreement as a two-stage partition function game with three symmetric players. This game, denoted as $\Gamma(N, \Pi)$, is fully defined by the set of countries, $N=\{1,2,3\}$, and the partition function, $\Pi$. The partition function $\Pi$ assigns payoffs to each country under each possible coalition structure, that is, under each partition of the set of countries. As explained below, we assume that only one non-trivial coalition will form. Here, non-trivial refers to a coalition with more than one country. Thus, a coalition structure is represented by $C=\left\{S, 1_{(3-m)}\right\}$, where $S$ represents the coalition composed of $m$ members, $m \in\{1,2,3\}$, and $1_{(3-m)}$ the vector of $3-m$ non-signatory countries acting as 
singletons. In this context, the overall coalition structure is fully characterized by the coalition $S$.

In the first stage of the game, each country decides whether to join the IFA (coalition) or remain a non-member and act as a singleton. We assume a setting with a single coalition and open membership (d'Aspremont et al., 1983), that is, only one coalition forms and any country is allowed to join the coalition. These assumptions are consistent with the legal setting of the United Nations Convention on the Law of the Sea (United Nations, 1982) and the United Nations Fish Stocks Agreement (United Nations, 1995), according to which an internationally shared fish stock should be managed through a Regional Fisheries Management Organization (RFMO). As stated in article 8 of the United Nations Fish Stocks Agreement, participation in an RFMO should be open to all countries with "a real interest in the fisheries concerned".

Our focus is on the number of countries that join the IFA. The usual approach to equilibrium coalition size is based on ideas developed for cartel stability (Barrett 1994, d'Aspremont et al., 1983 ) and requires what is called internal and external stability, which corresponds to a Nash equilibrium in membership strategies. Internal stability means that no signatory country has an incentive to leave the coalition $S$ to become a non-signatory, and external stability means that no non-signatory country has an incentive to join coalition $S$. The stability conditions are expressed formally as follows:

Internal stability: $\Pi_{i}^{*}(S) \geq \Pi_{i}^{*}(S \backslash\{i\}) \forall i \in S$

External stability: $\Pi_{j}^{*}(S)>\Pi_{j}^{*}(S \cup\{j\}) \forall j \notin S$.

In order to avoid unclear cases, we assume a strict inequality in the external stability condition. Thus, if a country is indifferent between joining coalition $S$ and remaining outside, it will join the agreement. Coalitions that are both internally and externally stable are called stable.

In the second stage, given that some coalition $S$ has formed in the first stage, countries choose their fishing effort levels in a non-cooperative setting. The $m$ signatories set their effort levels so as to maximize the aggregate payoff to their coalition:

$$
\begin{aligned}
& \max _{E_{S}} \sum_{i \in S} \Pi_{i}(S)= \\
& \sum_{i \in S} p q E_{i} \frac{k}{r}\left(r-q\left(\sum_{\ell=1}^{3} E_{\ell}\right)\right)-c \sum_{i \in S} E_{i}+m A \frac{k}{r}\left(r-q\left(\sum_{\ell=1}^{3} E_{\ell}\right)\right)\left(1-\frac{1}{2 r}\left(r-q\left(\sum_{\ell=1}^{3} E_{\ell}\right)\right)\right)
\end{aligned}
$$

where $E_{S}$ stands for a $m$-size vector with the fishing efforts of coalition $S$. 
Each singleton, $j$, chooses an effort level that maximizes its own payoff :

$$
\max _{E_{j}} \Pi_{j}=p q E_{j} \frac{k}{r}\left(r-q\left(\sum_{\ell=1}^{3} E_{\ell}\right)\right)-c E_{j}+A \frac{k}{r}\left(r-q\left(\sum_{\ell=1}^{3} E_{\ell}\right)\right)\left(1-\frac{1}{2 r}\left(r-q\left(\sum_{\ell=1}^{3} E_{\ell}\right)\right)\right) .
$$

The solution of the second stage non-cooperative game is obtained by solving problems (11) and (12) simultaneously, which yields the Nash equilibrium fishing efforts. Inserting these equilibrium fishing efforts into the countries' payoffs (equation 8), for each coalition structure, yields the partition function. Since the countries are symmetric, we assume an equal sharing of the coalitional worth. Finally, applying the conditions for internal and external stability, from (9) and (10), yields the equilibrium coalition structure. Thus, the game is solved backward for the subgame-perfect equilibrium.

Our model is a static two-stage game in which players sequentially decide whether to join the IFA (stage 1) and choose their fishing effort (stage 2) within a single period of time. Players' payoffs are computed based on steady-state stock levels. This approach is common in the fisheries literature (e.g. Long and Flaaten, 2011; Pintassilgo et al. 2010). A static two-stage game based on steady-state payoffs is also the framework most widely used for addressing international environmental agreements (IEAs), such as those on climate change (see Finus (2008) for a survey). The main advantage of this framework is its tractability, given the complexity of coalition formation games. As our model is the first analytical effort to integrate non-consumptive values into a fisheries coalition game, we adopt this workhorse framework.

In the following sections, we solve the fishing game using the backward induction sequence described above. Section 3 presents the solution to the second stage of the game, assuming that a coalition has been formed. Section 4 describes the solution to the first stage membership game, which determines the size of the IFA that will form.

\section{Results of the second stage: the fishing effort game}

There are three possible coalition structures that may arise as a result of the first stage membership game: full cooperation, partial cooperation and no cooperation. We next present the equilibrium fishing effort strategies and payoffs under each possible coalition structure.

\subsection{Full cooperation}

In the case of full cooperation, all three countries join the IFA, forming the grand coalition $S=\{1,2,3\}$. This coalition maximizes its aggregate worth: 


$$
\underset{E_{1}, E_{2}, E_{3}}{\operatorname{Max}} \sum_{i=1}^{3} \Pi_{i}=p q \sum_{j=1}^{3} E_{i} \frac{k}{r}\left(r-q\left(\sum_{i=1}^{3} E_{i}\right)\right)-c \sum_{i=1}^{3} E_{i}+3 A \frac{k}{r}\left(r-q\left(\sum_{i=1}^{3} E_{i}\right)\right)\left(1-\frac{1}{2 r}\left(r-q\left(\sum_{i=1}^{3} E_{i}\right)\right)\right) .
$$

From the first order conditions of this problem, we obtain the fishing effort of the coalition:

$$
E_{S}=\sum_{i=1}^{3} E_{i}=A E_{F C}=\frac{p r^{2}(1-b)}{q(2 r p+3 A)}
$$

where $A E_{F C}$ stands for aggregate effort under full cooperation and $b=\frac{c}{p q k}$.

Parameter $b=\frac{c}{p q k}$ is commonly termed the "inverse efficiency parameter" as it increases with the cost per unit of effort and decreases with price, catchability and carrying capacity of the ecosystem. In the absence of non-consumptive values, parameter $b$ is equal to the ratio of the open access equilibrium stock and the carrying capacity of the ecosystem (Pintassilgo et al., 2010). Therefore, $b \in[0,1[$, assuming that harvest is strictly positive under open-access.

Equation (13) indicates that the grand coalition aggregate effort $A E_{F C}$ decreases with $A$, which represents the magnitude of non-consumptive benefits. Moreover, $\lim _{A \rightarrow+\infty} A E_{F C}=0$. That is, if the non-consumptive benefits tend to infinity, then it is optimal not to harvest.

The equilibrium stock level is obtained by inserting the optimal fishing effort of the coalition in (13) into (4):

$$
X_{F C}^{*}=k\left(1-\frac{p r(1-b)}{(2 r p+3 A)}\right)
$$

The equilibrium payoff of the grand coalition is obtained by inserting the optimal fishing effort in the coalitional payoff:

$$
\Pi_{S}=\frac{p^{2} r^{2} k(1-b)^{2}}{2(2 r p+3 A)}+\frac{3 A k}{2}
$$

By differentiating expressions (14) and (15) with respect to parameter $A$ we conclude that both the stock level and the aggregate payoff increase with the non-consumptive benefits. Hence, as expected, if countries account for non-consumptive benefits and form a fully cooperative IFA, they will adopt more conservative fishing strategies, leading to larger stock levels. 


\subsection{Partial cooperation}

We next describe the equilibrium fishing effort strategies in the case of a two-country coalition.

Without loss of generality, we assume that the coalition is formed by countries 1 and 2, so that $S=\{1,2\}$.

The coalition again maximizes the joint payoff of its members:

$\underset{E_{1}, E_{2}}{\operatorname{Max}} \sum_{i=1}^{2} \Pi_{i}=p q \sum_{i=1}^{2} E_{i} \frac{k}{r}\left(r-q\left(\sum_{\ell=1}^{3} E_{\ell}\right)\right)-c \sum_{i=1}^{2} E_{i}+2 A \frac{k}{r}\left(r-q\left(\sum_{\ell=1}^{3} E_{\ell}\right)\right)\left(1-\frac{1}{2 r}\left(r-q\left(\sum_{\ell=1}^{3} E_{\ell}\right)\right)\right)$.

The singleton, country 3 , maximizes its own payoff:

$\underset{E_{3}}{\operatorname{Max}_{3}} \Pi_{3}=p q E_{3} \frac{k}{r}\left(r-q\left(\sum_{\ell=1}^{3} E_{\ell}\right)\right)-c E_{3}+A \frac{k}{r}\left(r-q\left(\sum_{\ell=1}^{3} E_{\ell}\right)\right)\left(1-\frac{1}{2 r}\left(r-q\left(\sum_{\ell=1}^{3} E_{\ell}\right)\right)\right)$.

Solving the first-order conditions to the two maximization problems simultaneously, we obtain the equilibrium fishing efforts of the coalition $S=\{1,2\}$ and the singleton country 3 :

$$
\begin{aligned}
& E_{S}=\frac{r(r p-A)(1-b)}{3 q(r p+A)} \\
& E_{3}=\frac{r(1-b)}{3 q}
\end{aligned}
$$

Differentiating (16) with respect to parameter $A$ shows that the fishing effort of the coalition decreases with $A$. Hence, the larger the non-consumptive benefits the lower is the equilibrium fishing effort of the coalition. However, the equilibrium effort of the singleton does not depend on the magnitude of the non-consumptive benefits. Here, two opposite effects cancel each other out. On the one hand, an increase in the non-consumptive benefits provides an incentive for the singleton to reduce its fishing effort. On the other hand, the accompanying reduction in the fishing effort of the coalition provides an incentive for the singleton to increase its fishing effort. In the equilibrium the singletons fishing effort remains unchanged.

The aggregate effort under partial cooperation is given by:

$$
A E_{P C}=E_{S}+E_{3}=\frac{2 r^{2} p(1-b)}{3 q(r p+A)} .
$$

Inserting (18) into (4) yields the equilibrium stock level: 


$$
X_{P C}^{*}=k\left(1-\frac{2 r p(1-b)}{3(r p+A)}\right)
$$

As in the case of full cooperation, the larger are the non-consumptive benefits from the stock, the lower is the aggregate fishing effort and consequently the higher is the equilibrium stock level.

Inserting the effort levels from (16) and (17) into the payoff expressions yields the equilibrium payoffs of the 2-country coalition and the singleton:

$$
\begin{aligned}
& \Pi_{S}=\frac{9 k A^{2}+3 p k r A\left(2-b^{2}+2 b\right)+r^{2} p^{2} k(1-b)^{2}}{9(r p+A)} \\
& \Pi_{3}=\frac{9 k A^{3}+6 r p k\left(4-2 b+b^{2}\right) A^{2}+r^{2} p^{2} k\left(13-8 b+4 b^{2}\right) A+2 r^{3} p^{3} k(1-b)^{2}}{18(r p+A)^{2}} .
\end{aligned}
$$

Both equilibrium payoffs increase with the magnitude of the non-consumptive benefits captured by parameter $A$, as can be confirmed by computing the respective derivatives. Under partial cooperation, larger non-consumptive benefits induce the countries forming the IFA to reduce their fishing effort. In contrast, the non-member chooses not to adjust its fishing effort, and instead free-rides on the conservation efforts of the IFA members. Overall, the aggregate fishing effort decreases, which results a larger equilibrium stock level.

\subsection{No Cooperation}

We now consider the case in which all the three countries behave as singletons. Each singleton $i \in\{1,2,3\}$ maximizes its own payoff:

$$
\operatorname{Max}_{E_{i}} \Pi_{i}=p q E_{i} \frac{k}{r}\left(r-q\left(\sum_{\ell=1}^{3} E_{\ell}\right)\right)-c E_{i}+A \frac{k}{r}\left(r-q\left(\sum_{\ell=1}^{3} E_{\ell}\right)\right)\left(1-\frac{1}{2 r}\left(r-q\left(\sum_{\ell=1}^{3} E_{\ell}\right)\right)\right) .
$$

Solving the first-order conditions to the three countries' maximization problems simultaneously yields the equilibrium fishing effort of each country:

$$
E_{i}=\frac{p r^{2}(1-b)}{q(4 r p+3 A)}
$$

Hence, the aggregate fishing effort under no cooperation is:

$$
A E_{N C}=\sum_{i=1}^{3} E_{i}=\frac{3 p r^{2}(1-b)}{q(4 r p+3 A)} \text {. }
$$


Under no cooperation, individual fishing efforts, and hence the aggregate effort, decrease with the magnitude of the non-consumptive benefits from the stock, denoted by $A$.

The stock level is obtained by inserting (23) into (4):

$$
X_{N C}^{*}=k\left(1-\frac{3 p r(1-b)}{(4 r p+3 A)}\right)
$$

The equilibrium payoff of each country is computed by inserting (22) and (23) into the payoff expression:

$$
\Pi_{i}=\frac{9 k A^{3}+24 p k r A^{2}+r^{2} p^{2} k\left(13+6 b-3 b^{2}\right) A+2 r^{3} p^{3} k(1-b)^{2}}{2(4 r p+3 A)^{2}} .
$$

Differentiating $\Pi_{i}$ with respect to the non-consumptive value parameter $A$ shows that each country's equilibrium payoff increases with the magnitude of non-consumptive benefits. As in the cases of full and partial cooperation, the higher are the non-consumptive benefits, the lower is the aggregate fishing effort and consequently the larger the stock level.

\subsection{Properties of the coalition formation game with non-consumptive values}

Based on the payoffs obtained for the three different coalition structures, we can now establish three important properties related to the second stage that will be helpful for the subsequent analysis.

Proposition 1. Properties of the Coalition Game.

Let $S$ and $S^{\prime}=S \cup\{j\}$ be two coalitions formed in the first stage of the game, where $S^{\prime}$ is obtained from the merger of coalition $S$ and country $j$.

(i) Positive Externalities: The payoff of country $\ell$, who is neither a member of coalition $S$ nor of $S^{\prime}$, is strictly higher under $S^{\prime}$ than under $S: \Pi_{\ell \notin S^{\prime}}\left(S^{\prime}\right)>\Pi_{\ell \notin S}(S)$;

(ii) Superadditivity: if $\# S=2$ (that is, the size of the coalition is two countries), then the sum of the payoffs of coalition $S$ and singleton $j$ is strictly lower than the payoff of $S^{\prime}=S \cup\{j\}$ : $\sum_{i \in S} \Pi_{i}(S)+\Pi_{j \notin S}(S)<\sum_{i \in S^{\prime}} \Pi_{i}\left(S^{\prime}\right)$, that is supperaditivity holds. If \# $S=1$ (that is, a 1-country coalition), then superadditivity does not hold: $\Pi_{i \in S}(S)+\Pi_{j \notin S}(S)>\sum_{i \in S^{\prime}} \Pi_{i}\left(S^{\prime}\right)$. 
(ii) Global Efficiency from Cooperation: The aggregate payoff (the sum of the payoffs of the three countries) is strictly higher under $S^{\prime}$ than $S$ :

$\sum_{i \in S^{\prime}} \Pi_{i}\left(S^{\prime}\right)+\sum_{\ell \notin S^{\prime}} \Pi_{\ell}\left(S^{\prime}\right)>\sum_{i \in S} \Pi_{i}(S)+\sum_{\ell \notin S} \Pi_{\ell}(S)$.

The proofs of this and all subsequent Propositions are shown in the Appendix.

Proposition 1 establishes that the game presents positive externalities, as the payoff of a singleton increases when the other two countries form a coalition. Positive externalities are usually referred to as the most important factor that inhibits the formation of large coalitions in the context of common pool resources and open membership (Finus, 2003). Another important property is superadditivity, which means that when countries join coalitions the sum of the payoffs of merging countries increases. In other words, a larger cooperation increases the aggregate payoff of the countries involved, creating a force towards cooperation. We show that superadditivity does not hold under all coalition structures. This result was also found by Pintassilgo et al. (2010) in an analysis of IFAs in the absence of non-consumptive values. Superadditivity fails to hold when singletons merge to form a 2-country coalition, which intensifies the free-rider problem emerging from the positive externality property. Superadditivity instead does hold when a singleton joins a 2-country coalition to form the grand coalition, which provides a force towards cooperation. However, in this case the positive externality effect is stronger, so that free-riding remains attractive. Finally, global efficiency from cooperation implies that the aggregate payoff increases along with the number of countries joining the coalition. Thus, more extensive cooperation produces larger aggregate payoffs, and the maximum aggregate payoff is obtained under the grand coalition.

Proposition 2. The aggregate effort level decreases with coalition size and with the magnitude of non-consumptive benefits under all coalition structures.

Proposition 2 establishes that the more countries join an IFA, the lower the aggregate fishing effort and, consequently, the larger the stock size. This is one of the core driving forces of the game. Larger cooperation translates into conservation of the stock and consequently into larger aggregate payoff (global efficiency from cooperation). Furthermore, large non-consumptive benefits, as measured by parameter $A$, reduce aggregate fishing effort and increase stock size. Hence, both cooperation and non-consumptive values result in the conservation of the shared fish resource. 


\section{Results of the first stage: the membership game}

Given the equilibrium fishing effort strategies for each possible coalition structure, derived in Section 3, we can now solve the membership game that takes place in the first stage. As players are symmetric, an equal sharing of the coalitional worth is assumed.

Proposition 3. The equilibrium coalition structure is no cooperation irrespective of the magnitude of the non-consumptive values.

Proposition 3 shows that accounting for non-consumptive values does not change the outcome found by Pintassilgo and Lindroos (2008) for shared fisheries with only commercial profits (use values from harvest). That is, the equilibrium coalition structure is always full non-cooperation. The trap of non-cooperation persists despite countries attributing non-consumptive values to the stock and regardless of the magnitude of non-consumptive values.

The presence of non-consumptive values has an effect on the second stage game: countries reduce their fishing effort under all possible coalition structures, which leads to stock conservation relative to the case without non-consumptive values. However, the outcome of the first stage remain unchanged: countries continue to have incentives to free-ride coalitions (IFAs), which results in full non-cooperation.

\section{Outcome of the coalition formation game with asymmetry in non-consumptive values}

Pintassilgo et al. (2010) show that cost asymmetry may overcome the trap of full noncooperation. Moreover, the likelihood of large IFAs increases with cost asymmetry. We next investigate whether asymmetry on the magnitude of non-consumptive values has similar effects.

We now consider the case where non-consumptive values, as measured by the parameter $A_{i}$, differ among the countries:

$$
v_{i}(X)=A_{i} X\left(1-\frac{X}{2 k}\right), i \in\{1,2,3\} .
$$

Thus, the steady-state payoff of each country is given by

$$
\Pi_{i}=p q E_{i} \frac{k}{r}\left(r-q\left(\sum_{\ell=1}^{3} E_{\ell}\right)\right)-c E_{i}+A_{i} \frac{k}{r}\left(r-q\left(\sum_{\ell=1}^{3} E_{\ell}\right)\right)\left(1-\frac{1}{2 r}\left(r-q\left(\sum_{\ell=1}^{3} E_{\ell}\right)\right)\right) .
$$

In a context of asymmetric players, several sharing schemes can be applied to divide the coalitional worth. Thus, the following question arises: for a given coalition $S$, can a sharing 
rule be found that stabilizes the coalition? A necessary condition for stabilizing a coalition is that the coalitional worth be at least as large as the sum of the players' free-rider payoffs when leaving the coalition. This condition is usually termed potential internal stability, formally defined as

Potential internal stability: $\Pi_{S}(S) \geq \sum_{i \in S} \Pi_{i}(S \backslash\{i\})$.

This condition states that only if the coalitional worth (weakly) exceeds the sum of the players' free-rider payoffs, is it possible to find a sharing rule under which no coalition member has an incentive to leave the coalition.

Proposition 4. The only potentially internally stable coalition structure is the one formed by singletons.

According to Proposition 4, there is no sharing rule that can make full or partial cooperation internally stable. Thus, the only possible stable coalition structure is full non-cooperation. This coalition structure is often considered stable by definition: if all countries first announce that they will not join the IFA, then a unilateral decision by one country to join the IFA after all makes no difference, which ensures external stability (see for instance Finus and Pintassilgo, 2013). Therefore, even if countries differ in terms of the magnitude of their non-consumptive values, this asymmetry is not sufficient to induce them to cooperate in managing the shared fish stock.

\section{Conclusion}

This paper presents a model of coalition formation in transboundary fisheries management in the case where countries take into account both profits from harvesting and non-consumptive values from the fish stock per se. While the three-country model presented is relatively simple, it suffices to highlight the strategic interactions in play when a fish stock migrates across the boundaries between the waters of several countries, or resides in the high seas.

In contrast to previous papers on transboundary fisheries management with non-consumptive values, where analysis was limited to a two-country framework, the present paper analyses coalition formation and shows that accounting for non-consumptive values does not affect the outcome in terms of the prospects for cooperation. Although accounting for non-consumptive values decreased the aggregate fishing effort under all possible coalition scenarios (full, partial and no cooperation), the outcome of the game was full non-cooperation. This result holds regardless of the magnitude of the non-consumptive values. That is, including non-consumptive 
values does not suffice to overcome the trap of non-cooperation in transboundary fisheries management.

We also extended the game to the case where the countries are asymmetric regarding nonconsumptive values. We found that irrespective of the asymmetry, cooperation could not be sustained as the outcome of the game. This result is in contrast with previous findings by, e.g., Pintassilgo et al. (2010), where large asymmetries in terms of harvesting costs led to formation of large coalitions. Asymmetries in harvesting costs make coalitions more appealing as harvests can be undertaken by the members with the lowest costs. There is no similar effect in the case of asymmetries in non-consumptive values. Thus, while accounting for non-consumptive values resulted in conservation of the stock in the sense that aggregate effort under full noncooperation was smaller than in the case where countries did not receive benefits from the fish stock per se, it did not improve the prospects for cooperation.

A key message that emerges from our analysis is that cooperation in the management of internationally shared fish stocks cannot be fostered by accounting for non-consumptive values. Hence, other measures are required to stabilize IFAs. These measures should strengthen the role of IFAs in the management of the resources and limit the ability of non-member countries to free-ride. For instance, Kwon (2006) and Long and Flaaten (2011) show that the prospects of cooperation are much higher if the coalition takes the role of a Stackelberg leader in fishing effort decisions. Munro (2007) stresses the need to address the so called "unregulated fishing", that is, fishing activities undertaken in the high seas in contravention of the management regime set by the IFA, by countries that did not join the agreement.

The pessimist results obtained in this paper regarding cooperation in IFAs should be regarded with caution. They stem from a complex coalition formation model with several structural assumptions. In particular, the model assumes a logistic growth function, harvesting costs that are linear in fishing effort, and quadratic non-consumptive value functions. While all these are standard assumptions, we acknowledge that departing from them may lead to different outcomes. Another important assumption of our model is that of internal and external stability, by which countries can deviate from IFAs unilaterally. Farsighted stability would be an alternative behavioural assumption. Under farsighted stability, countries foresee that by deviating from an IFA they might trigger deviations by other members, which makes free riding less appealing. Previous studies have shown that farsighted stability leads to larger cooperation levels (e.g., Breton and Keoula, 2012; de Zeeuw, 2008). The use of a static game based on steady state payoffs is also a limitation of our model. Departing to a dynamic coalition 
formation game, in which players could revise their membership over time, could provide interesting additional insights.

Our analysis did not include non-commercial use values from recreational harvest. In essence, benefits from recreational harvest could be modelled similarly to those from commercial harvest, as a function of recreational fishing effort (see, e.g., Kulmala et al., 2008). A potential topic for future research would be to examine whether asymmetries in use values attributable to recreational harvest could help sustain cooperation as the outcome of the game. Another potential topic for future research would be to extend the game to any number of players. We anticipate that the results would be similar, in that non-consumptive values would not be sufficient to break the trap of non-cooperation. This is due to the fact that coalition formation games applied to IFAs with three countries contain the main driving forces present in games with larger number of countries. Finally, it would also be interesting to examine how the order in which countries harvest the stock affects the prospects for cooperation. Here, we proceeded from the assumption that countries move simultaneously. As indicated in Kwon (2006) and Long and Flaaten (2011), a game structure where countries move sequentially, with one country acting as a leader, for instance because of geographic proximity to the fish stock, could yield different conclusions regarding the potential for cooperation. All these extensions are left for further studies. 


\section{References}

Alexander, R., 2000. Modelling species extinction: the case of non-consumptive values. Ecological Economics 35, 259-269.

Arrow, K., Solow, R., Portney, P., Leaner, E., Radner, R., Schuman, H., 1993. Report of the NOAA Panel on Contingent Valuation. Fed. Reg. 58, 4602-4614.

Bailey, M., Sumaila, U.R., Lindroos, M., 2010. Application of game theory to fisheries over three decades. Fisheries Research 102, 1-8.

Barrett, S., 1994. Self-enforcing international environmental agreements. Oxford Economic Papers 46, 878-894.

Brandt, U.S., Kronbak, L.G., 2010. On the stability of fishery agreements under exogenous change: An example of agreements under climate change. Fisheries Research 101, 11-19.

Breton, M., Keoula, M., 2012. Farsightedness in a coalitional great fish war. Environmental \& Resource Economics 51, 297-315.

Breton, M., Keoula, M., 2014. A great fish war model with asymmetric players. Ecological Economics 97, 209-223.

Conrad, J., Clark, C., 1987. Natural Resource Economics - Notes and Problems, Cambridge University Press, New York.

d'Aspremont, C., Jacquemin, A., Gabszewicz, J.J., Weymark, J.A., 1983. On the stability of collusive price leadership. Canadian Journal of Economics 16(1), 17-25.

de Zeeuw, A. 2008. Dynamic effects on the stability of international environmental agreements. Journal of Environmental Economics and Management 55:163-174.

Ferrara, I., Missios, P., 1998. Non-use values and the management of transboundary renewable resources. Ecological Economics 25, 281-289.

Finus, M., 2003. Stability and design of international environmental agreements: the case of global and transboundary pollution, in: Folmer, H., Tietenberg, T. (Eds.), International Yearbook of Environmental and Resource Economics 2003/4. Edward Elgar, Cheltenham pp $82-158$.

Finus, M., 2008. Game theoretic research on the design of international environmental agreements: insights, critical remarks and future challenges. International Review of Environmental and Resource Economics 2(1), 29-67.

Finus, M., Pintassilgo, P., 2013. The role of uncertainty and learning for the success of international climate agreements. Journal of Public Economics 103, 29-43.

Freeman III, A.M., 2003. The Measurement of Environmental and Resource Values: Theory and Practise, second ed. Resources for the Future, Washington, DC.

Hannesson, R. 2013. Zonal attachment of fish stocks and management cooperation. Fisheries Research 140, 149-154.

Håkansson, C., 2008. A new valuation question: analysis of and insights from interval openended data in contingent valuation. Environmental and Resource Economics 39(2), 175-188.

Harstad, B., Liski, M., 2012. Games and resources, NBER Working Paper No. 18519.

Jensen, F., Frost, H., Thøgersen, T., Andersen, P., Andersen, J.L., 2015. Game theory and fish wars: The case of the Northeast Atlantic mackerel fishery. Fisheries Research 172, 7-16. 
Kulmala, S., Laukkanen, M., Michielsens, C., 2008. Reconciling economic and biological modeling of migratory fish stocks: Optimal management of the Atlantic salmon fishery in the Baltic Sea. Ecological Economics 64, 716-728.

Kulmala S., Levontin P., Lindroos M., Pintassilgo, P., 2013. Atlantic salmon fishery in the Baltic Sea - a case of trivial cooperation? Strategic Behavior and the Environment 3(1-2), 121147.

Kwon, O., 2006. Partial international coordination in the great fish war. Environmental \& Resource Economics 33(4), 463-483.

Lasserre, P., Smulders, S., 2013. An ABC of nonrenewable-renewable resource interactions: Antibiotics, Biofuels, Carbon Decay, Expropriation, Forestry,... Resource and Energy Economics 25, 558-571.

Liu, Y., Diserud, O.H., Hindar, K., Skonhoft, A., 2013. An ecological-economic model on the effect of interactions between escaped farmed and wild salmon (Salmo salar). Fish and Fisheries 14, 158-173.

Long, L.K., Flaaten, O., 2011. A Stackelberg analysis of the potential for cooperation in straddling stock fisheries. Marine Resource Economics 26, 119-139.

Loomis, J. B., White, D.S., 1996. Economic benefits of rare and endangered species: summary and meta-analysis. Ecological Economics 18(3), 197-206.

Mazzanti, M., 2001. The role of economics in global management of whales: reforming or refounding IWC? Ecological Economics 36, 205-221.

Millennium Ecosystem Assessment, 2005. Ecosystems and Human Well-being: Synthesis. Island Press, Washington, DC, pp. 1-55.

Missios, P., Plourde, C., 1997. Transboundary renewable resource management and conservation motives. Marine Resource Economics 12, 29-36.

Munro, G., 1979. The optimal management of transboundary renewable resources. Canadian Journal of Economics 12(3), 355-376.

Munro, G., 2007. Internationally shared fish stocks, the high seas, and property rights in fisheries. Marine Resource Economics 22, 425-443.

Olaussen, J.O., Liu, Y., Skonhoft, A., 2015. Conservation versus harvest of wild Atlantic salmon. The cost of sea lice induced mortality. Fisheries Research 168, 63-71.

Pintassilgo, P., 2003. A coalition approach to the management of high seas fisheries in the presence of externalities. Natural Resource Modeling 16, 175-197.

Pintassilgo, P., Lindroos, M., 2008. Coalition formation in straddling stock fisheries: a partition function approach. International Game Theory Review 10(3), 303-317.

Pintassilgo, P., Finus, M., Lindroos, M., Munro, G., 2010. Stability and success of regional fisheries management organizations. Environmental and Resource Economics 46(3), 377-402.

Pintassilgo, P., Kronbak, L.G., Lindroos, M., 2015. International fisheries agreements: A game theoretical approach. Environmental and Resource Economics 62(4), 689-709.

Punt, M., Weikard, H-P., van Ierland E., 2013. Marine protected areas in the high seas and their impact on international fishing agreements. Natural Resource Modeling 26(2):164-193.

Randall, A., Ives, B., Eastman, C., 1974. Bidding games for valuation of aesthetic environmental improvements. Journal of Environmental Economics and Management 1, 132149. 
Smith, V.K., 2000. JEEM and non-market valuation: 1974-1998. Journal of Environmental Economics and Management 39, 351-374.

Turner, R.K., Paavola, J., Cooper, P., Farber, S., Jessamy, V., Georgiou, S., 2003. Valuing nature: lessons learned and future research directions. Ecological Economics 46(3), 493-510.

United Nations, 1982. United Nations Convention on the Law of the Sea. UN Doc. A/Conf.62/122.

United Nations, 1995. United Nations Conference on Straddling Fish Stocks and Highly Migratory Fish Stocks. Agreement for the Implementation of the Provisions of the United Nations Convention on the Law of the Sea of 10 December 1982 Relating to the Conservation and Management of Straddling Fish Stocks and Highly Migratory Fish Stocks. UN Doc. A/Conf./164/37.

Yamazaki, S., Grafton, Q., Kompas, T., 2010. Non-consumptive values and optimal marine reserve switching. Ecological Economics 69, 2427-2434. 


\section{Appendix}

\section{Proof of Proposition 1.}

(i) In our game, the analysis of positive externalities is confined to the change from no cooperation to partial cooperation, as it is required that one country remain outside both the initial and the final coalition. Let $S$ be a 1-country coalition, $S^{\prime}$ a 2-country coalition, and country $\ell$ neither a member of coalition $S$ nor of $S^{\prime}$. Then, using the payoffs in (25) and (21), we obtain:

$$
\Pi_{\ell \in S^{\prime}}\left(S^{\prime}\right)-\Pi_{\ell \in S}(S)=\frac{r(-p q k+c)^{2}(A+2 r p)(6 A+7 r p)(3 A+r p)^{2}}{18 p q^{2} k(r p+A)^{2}(4 r p+3 A)^{2}}
$$

This expression is always positive, which proves that the game exhibits positive externalities.

(ii) Consider $\# S=2$. Then using (15), (20) and (21) we obtain:

$$
\sum_{i \in S^{\prime}} \Pi_{i}\left(S^{\prime}\right)-\left(\sum_{i \in S} \Pi_{i}(S)+\Pi_{j \notin S}(S)\right)=\frac{r^{2}(-p q k+c)^{2}(3 A+r p)^{2}}{18 k(2 r p+3 A) q^{2}(r p+A)^{2}}
$$

This expression is always positive and hence superadditivity holds for $\# S=2$.

Consider now $\# S=1$. Then using (20) and (25) we obtain:

$$
\sum_{i \in S^{\prime}} \Pi_{i}\left(S^{\prime}\right)-\left(\sum_{i \in S} \Pi_{i}(S)+\Pi_{j \notin S}(S)\right)=-\frac{r(-p q k+c)^{2}(3 A+2 r p)(3 A+r p)^{2}}{9 p q^{2} k(4 r p+3 A)^{2}(r p+A)}
$$

This expression is always negative and hence superadditivity does not hold for $\# S=1$.

(iii) In order to prove this property it is sufficient to analyse the cases of $\# S=1$ and $\# S=2$. For $\# S=2$, the proof of global efficiency is identical to the proof of superadditivity in (ii). If $\# S=1$, then, using (20), (21) and (25), we obtain:

$$
\sum_{i \in S^{\prime}} \Pi_{i}\left(S^{\prime}\right)+\sum_{\ell \notin S^{\prime}} \Pi_{\ell}\left(S^{\prime}\right)-\left(\sum_{i \in S} \Pi_{i}(S)+\sum_{\ell \notin S} \Pi_{\ell}(S)\right)=\frac{r^{2}(-p q k+c)^{2}(9 A+10 r p)(3 A+r p)^{2}}{18 q^{2} k(r p+A)^{2}(4 r p+3 A)^{2}}
$$

This expression is always positive and therefore global efficiency always hold for $\# S=1$. 


\section{Proof of Proposition 2.}

From (13), (18) and (23), the aggregate efforts under full cooperation, partial cooperation and no cooperation are given by:

$$
A E_{F C}=\frac{p r^{2}(1-b)}{q(2 r p+3 A)} ; \quad A E_{P C}=\frac{2 p r^{2}(1-b)}{3 q(r p+A)} ; \quad A E_{N C}=\frac{3 p r^{2}(1-b)}{q(4 r p+3 A)} .
$$

Applying some algebraic manipulations to the aggregate effort expressions yields the following comparisons:

$$
\begin{aligned}
& A E_{F C}-A E_{P C}=-\frac{r^{2}(1-b)(r p+3 A)}{3 p(2 r p+3 A) q(r p+A)} \\
& A E_{P C}-A E_{N C}=-\frac{r^{2}(1-b)(r p+3 A)}{p(4 r p+3 A) q(r p+A)} .
\end{aligned}
$$

As $0 \leq b<1$, both expressions are negative.

It follows directly from the expressions of the three aggregate efforts levels that they decrease with parameter $A$.

\section{Proof of Proposition 3.}

The grand coalition $\{1,2,3\}$ is not a stable coalition structure, as the internal stability condition (9) does not hold. Applying the equal sharing rule to the payoff (15) and using (21), we obtain

$$
\begin{aligned}
\Pi_{i}^{*}(\{1,2,3\})-\Pi_{i}^{*}(\{1,2,3\} \backslash\{i\}) & =-\frac{r(-p q k+c)^{2}(2 A+r p)(3 A+r p)^{2}}{18 k(2 r p+3 A) q^{2} p(r p+A)^{2}} \\
& <0, \quad \forall i \in\{1,2,3\} .
\end{aligned}
$$

The expression on the right hand side is always negative and hence condition (9) does not hold.

The 2-country coalitions are also not internally stable. Applying the equal sharing rule to the payoff in (20) and using (25) yields

$$
\Pi_{i}^{*}(\{1,2\})-\Pi_{i}^{*}(\{1,2\} \backslash\{i\})=-\frac{r(-p q k+c)^{2}(2 r p+3 A)(3 A+r p)^{2}}{p q^{2} k(r p+A)(4 r p+3 A)^{2}}<0, \forall i \in\{1,2\} .
$$


According to (A9) the difference between the payoff of any country in a 2-country coalition $\{1,2\}$ and the payoff to the country after leaving that coalition is negative. Therefore, 2-country coalitions are also not internally stable.

The coalition structure formed only by singletons is internally stable by definition. Since the countries are symmetric by assumption, this coalition structure is also externally stable as the 2-country coalitions are not internally stable. The coalition structure formed by singletons is therefore stable and the unique equilibrium coalition structure.

\section{Proof of Proposition 4.}

By solving the second stage fishing effort game and the first stage membership game along the lines of Sections 3 and 4, we obtain the following expressions for the aggregate fishing effort and equilibrium stock levels for each possible coalition structure:

$$
\begin{aligned}
& A E_{F C}=\frac{p r^{2}(1-b)}{q\left(2 r p+\sum_{i=1}^{3} A_{i}\right)} ; A E_{P C}=\frac{2 r^{2} p(1-b)}{q\left(3 r p+\sum_{i=1}^{3} A_{i}\right)} ; A E_{N C}=\frac{3 p r^{2}(1-b)}{q\left(4 r p+\sum_{i=1}^{3} A_{i}\right)} . \\
& X_{F C}^{*}=k\left(1-\frac{p r(1-b)}{2 r p+\sum_{i=1}^{3} A_{i}}\right) ; X_{P C}^{*}=k\left(1-\frac{2 r p(1-b)}{3 r p+\sum_{i=1}^{3} A_{i}}\right) ; X_{N C}^{*}=k\left(1-\frac{3 p r(1-b)}{4 r p+\sum_{i=1}^{3} A_{i}}\right) .
\end{aligned}
$$

Computing the difference between the coalitional worth and the sum of the players' free-rider payoffs when leaving the coalition, we get for the 3-player and 2-player coalitions, respectively:

$$
\begin{aligned}
& \Pi_{\{1,2,3\}}(\{1,2,3\})-\sum_{i=1}^{3} \Pi_{i}(\{1,2,3\} \backslash\{i\})=-\frac{r\left(3 p r+2 \sum_{i=1}^{3} A_{i}\right)\left(p r+\sum_{i=1}^{3} A_{i}\right)^{2}(-p q k+c)^{2}}{2 k q^{2} p\left(2 p r+\sum_{i=1}^{3} A_{i}\right)\left(3 p r+\sum_{i=1}^{3} A_{i}\right)^{2}} \\
& \Pi_{\{i, j\}}(\{i, j\})-\left(\Pi_{i}(\{i, j\} \backslash\{i\})+\Pi_{j}(\{i, j\} \backslash\{j\})\right)= \\
& -\frac{r\left(p r\left(4 p r+A_{i}+A_{j}+8 A_{z}\right)+2 A_{z}\left(\sum_{\ell=1}^{3} A_{\ell}\right)\right)\left(p r+\sum_{\ell=1}^{3} A_{\ell}\right)^{2}(-p q k+c)^{2}}{2 k q^{2} p\left(4 p r+\sum_{\ell=1}^{3} A_{\ell}\right)^{2}\left(3 p r+\sum_{\ell=1}^{3} A_{\ell}\right)^{2}}
\end{aligned}
$$

where $i, j, z \in\{1,2,3\}$ and $z$ refers to the country not in $\{i, j\}$. 
Expressions (A12) and (A13) are both negative. Therefore, neither the grand coalition nor any 2-country coalitions satisfy the potential internal stability condition (28). The singleton coalition structure is potentially internally stable by definition, as no further exits from a coalition are possible. 


\section{Response to Referee 1}

We would like to thank the referee for an insightful review of our paper. Below we go through the specific comments and explain how we have accounted for them in the revised manuscript.

This is a very well written paper, which needs little or no revision. It extends the results from other papers on international fisheries agreements to the case where fish also have non-consumptive value. A couple of details are that ( $i$ ) the authors could alert the reader explicitly to the fact that Propositions 3 and 4 are proven in the appendix, as the first two. Furthermore, (ii) the effort and stock functions are not shown for the case when countries have different non-consumptive valuations of the stock.

We are happy that the referee regards our paper with a positive view.

In page 14 we now highlight after Proposition 1 that "The proofs of this and all subsequent Propositions are shown in the Appendix." This and all other changes to the paper are shown in blue colour.

The effort and stock functions in the case where countries have different non-consumptive valuations of the stock are now included in the Appendix (equations (A10) and (A11)).

The paper reaches a very pessimistic conclusion with regard to the possibilities for cooperation. The reason is the way the fisheries game is set up, an approach that this paper shares with many other game-theoretic papers. The road to the conclusion is as follows. First it is shown that any single participant would be better off as a free rider than under full cooperation, provided all the rest ( $a$ coalition of 2) will continue cooperating. Then, it is shown that the remaining coalition (of 2) would also break up, for the same reason. We thus end up with no cooperation at all. But in that situation, each and everyone is worse off than under cooperation. It could therefore be argued that if all participants foresee where the process of non-cooperation ends up, full cooperation would indeed prevail, as a far-sighted equilibrium (de Zeeuw, Dynamic Effects on the Stability of International Environmental Agreements, JEEM 55:163-74).

We agree that far-sighted equilibrium would be a way to obtain more optimistic results. This argument has now been introduced in the conclusion (page 17, last paragraph). 


\section{Response to Referee 2}

We would like to thank the referee for an insightful review of our paper. Below we go through the specific comments and explain how we have accounted for them in the revised manuscript.

This paper investigates management of shared fish stocks and whether it is possible to reach a stable coalition for such stocks. In relation to this issue, Pintassilgo and Lindroos (2008) show that it is not possible to enter any coalitions between the players when the profit is the only component of a manager's objective function. In the present paper the objective function in Pintassilgo and Lindroos (2008) is extended to include non-consumption values and it is shown that the results in Pintassilgo and Lindroos (2008) still hold under this assumption.

The present paper is well-written but it is a mathematical paper. Given the mathematical style it can be questioned whether Fisheries Research is the outlet for publishing the paper but this is up to the Editor to decide. I, also, have a number of problems with the assumptions and mathematical derivations in the paper and these are sketched below:

We recognize that the paper has a significant mathematical content. In order to make it accessible to a general audience we chose to make the abstract, introduction and conclusion free from technical concepts. Moreover, all proofs of the results were inserted into an Appendix.

1. The analysis in the paper is based on a logistic growth function and a Schaefer production function. As always when using specific functional forms it is unclear whether the results generalize to other functional forms. This issue must be discussed.

The logistic growth function and the Schaefer production function are commonly used in coalition formation games applied to fisheries due to its simplicity. The adoption of other functional forms may, however, lead to different results. We now acknowledge this limitation in the conclusion (page 17, last paragraph). This and all other changes to the paper are shown in blue colour.

2. You assume a steady-state equilibrium and it must be discussed whether this assumption is reasonable. In reality, fisheries are never in a steady-state and if adjustments towards steady-state are taken into account a dynamic game approach ought to be used.

This is very relevant point. We now address it in Section 2.2, Coalition formation model, page 9, $2^{\text {nd }}$ paragraph after equation (12). We also mention it as a limitation of our analysis in the Conclusion 
(page 17, last paragraph). A static 2-stage game based on steady-state payoffs is a very common framework in coalition formation games addressing fisheries (e.g. Long and Flaaten, 2011; Pintassilgo et al. 2010; Pintassilgo and Lindroos, 2008). It is also the framework used most commonly to analyse international environmental agreements, such as those on climate change (Finus, 2008). The reason for the prevalence of this framework is its tractability, given the large complexity involved in a coalition formation game. A dynamic coalition formation game (e.g. Rubio and Ulph, 2007 on international environmental agreements) raises significantly the complexity of the model, making it difficult to understand the driving forces in the model. As our model is the first analytical effort to integrate non-consumptive values into a fisheries coalition game, we think that the simpler static workhorse framework is a good starting point (as mentioned now in page $9,2^{\text {nd }}$ paragraph after equation 12).

Within your model at least two problems arise with the steady-state assumption. First, you set-up a two-stage game. What happens if the optimal fish stock change between the two stages in the game?

Although there are two stages in the decision process, both decisions are taken in the same period of time. We now make this clear on page $9,2^{\text {nd }}$ paragraph after equation (12). Allowing the stock to change between stages would require a dynamic coalition formation model.

Second, in the second stage of the game you discuss three alternative coalition structures represented by full cooperation, partial cooperation and no cooperation. However, the optimal fish stock differs between these coalition structures. What are the implications of the steady-state assumptions in relation to this fact?

This is one of the core driving forces of the game. The larger the cooperation level, the lower the steady state aggregate fishing efforts and consequently the larger the fish stock. Larger cooperation translates into conservation of the stock and also larger aggregate payoff (global efficiency from cooperation). This is now mentioned in page 14, lines 2-4 after Proposition 2.

3. You assume that the cost per unit of effort and the price is constant. At the same time you assume that the non-consumption value is quadratic in the stock size. I think the assumptions should be consistent leading to the suggestion that a linear total non-consumption value should be assumed. Furthermore, a quadratic nonconsumption value creates a problem if adjustments towards steady-state are 
allowed. With a linear objective function a bang-bang solution is optimal while a non-linear objective function implies that a gradual adjustment towards steadystate is optimal. Thus, when including a quadratic non-consumption value you move from a bang-bang solution (without a non-consumption value) to a gradual adjustment (with a non-consumption value) if a dynamic model is used. I believe that it would be useful to set-up the model so that the implications for the adjustments towards the steady-state are the same. So this provides another argument for using a linear total non-consumption value.

A strictly concave non-consumption value is a standard assumption in natural resource valuation (Freeman III, 2003) and has also been adopted in the fisheries literature (e.g., Liu, 2013; Olaussen et al., 2015). It implies that society attributes a decreasing marginal value to the stock for nonconsumptive purposes. This is now referred in the paper in Section 2.1 (Bioeconomic model), page 6, lines 4-7 after equation (5). As we use a static game the adjustment to the steady state is not considered. That additional complexity would arise in the context of a dynamic game.

4. I do not understand the derivations leading to (7). You assume that the nonconsumption value increase in the stock size until $k$ is reached implying that $v(X)$ reach a maximum at $k$. Now you impose the first-order condition that $v^{\prime}(X)=0$ to reach the relation that $B=A / 2 k$. This relation is then inserted into (6) to reach (7). However this derivation is based on the assumption that the manager maximize the non-consumption value given that the first-order condition is used $\left(v^{\prime}(X)=0\right)$. But within your model the manager maximize the sum of the profit and nonconsumption value leading to the conclusion that you cannot use $v^{\prime}(X)=0$ to reach (7). Maybe I am wrong here but in this case you must explain how (7) is reached.

Having adopted a quadratic non-consumptive value function, $v(X)$, we added two other assumptions in order to simplify the model. The first is that there is no non-consumptive value when the stock is extinct $(v(X=0)=0)$. The second is that the maximum non-consumptive value occurs when the stock is at the carrying capacity of the environment, $\mathrm{k}$. That is, if the stock goes beyond the carrying capacity of the environment then the marginal non-consumptive value becomes negative. This is a simplifying assumption which makes the model easier to solve and is independent of the maximization problem of the manager who maximizes the sum of profits and non-consumptive values. We tried to clarify this point in page 6 (lines 4-7 after equation (5)) and page 7 (paragraph after equation (6)). 
5. You consider a two-stage game but within you model this raises two problems. First, a two-stage game require that two distinct time periods can be identified and this is not totally clear within your model. Instead you set-up two totally maximization problems in the two-stages so basically you must justify why the two problems are solved in two distinct time periods. Second, if you have two distinct time periods you ought to include discounting of the payoffs in the second stage. These two issues must be addressed.

We now make it clear that it is a static game in which the two stages occur within a single period (see Section 2.2, Coalition formation model, page $9,2^{\text {nd }}$ paragraph after equation (12)).

6. In fact the second stage of the game is a non-cooperative game and this is not clear from the text now. This may be seen from the fact that the aggregated effort of all three players enters in the payoff functions for the players under partial cooperation and no cooperation. In this perspective you assume Cournot-Nash expectation when you derive the first-order conditions and the solution for the effort levels and stock size represent a Nash equilibrium. This must be explicitly stated.

This aspect is now explicitly mentioned in Section 2.2 (Coalition formation model), page 8 (two lines before equation (11)) and page 9 (lines 1-2 after equation (12)).

7. I think the implications of only having three players should be discussed. Here it is natural that it becomes even more difficult to reach full cooperation.

We now discuss this point in the conclusion (page 18, lines 7-12).

8. I find it difficult to understand why it is not possible to reach full cooperation for all possible values of $v(X)$. Specifically, what is the driver behind the result if $v(X) \rightarrow \propto$. Thus, you must intuitively explain why the result in Pintassilgo and Lindroos (2008) generalizes to the inclusion of non-consumption values in the manager's objective function.

We agree that this is not a straightforward result. In fact, when we incorporated non-consumptive values into the model, we expected that they could affect cooperation. It turns out that they clearly affect the outcomes of the second stage game, leading to lower fishing efforts and hence stock conservation. However, the outcome of the first stage remain unchanged: countries continue to have 
incentives to free-ride coalitions (IFAs), leading to full non-cooperation. The driver behind the result seems to be the following: when $v(X)$ increases, coalition members decrease their fishing effort and hence contribute to a larger stock level. In this context, non-members continue to find it optimal to free-ride. This is now discussed in the last paragraph of Section 4.

9. In proposition 3 you state that the equilibrium coalition structure is no cooperation in all possible situations. However, in appendix you only show this for the equal sharing rule. If proposition 3 shall hold it must be shown for all possible sharing rules.

As players are symmetric "an equal sharing of the coalitional worth is assumed.". This is now also stated just before Proposition 3, as well as in Section 2.2. (lines 4-5 after equation (12)). 